A N N A LES

UNIVERSITATIS MARIAE CURIE-SKŁODOWSKA

LUBLIN - POLONIA

\title{
A new iterative method for generalized equilibrium and constrained convex minimization problems
}

\begin{abstract}
The gradient-projection algorithm (GPA) plays an important role in solving constrained convex minimization problems. In this paper, we combine the GPA and averaged mapping approach to propose an explicit composite iterative scheme for finding a common solution of a generalized equilibrium problem and a constrained convex minimization problem. Then, we prove a strong convergence theorem which improves and extends some recent results.
\end{abstract}

1. Introduction. Let $H$ be a real Hilbert space and $C$ be a nonempty closed convex subset of $H$. A mapping $T$ of $C$ into itself is called nonexpansive, if $\|T x-T y\| \leq\|x-y\|$ for all $x, y \in C$. Also, a contraction on $C$ is a self-mapping $f$ of $C$ such that $\|f(x)-f(y)\| \leq k\|x-y\|$ for all $x, y \in C$, where $k \in(0,1)$ is a constant. Moreover, $F(T)$ denotes the fixed points set of $T$.

Let $\phi: C \times C \rightarrow \mathbb{R}$ be a bifunction of $C \times C$ into $\mathbb{R}$. The equilibrium problem for $\phi: C \times C \rightarrow \mathbb{R}$ is to find $u \in C$ such that

$$
\phi(u, v) \geq 0, \quad \text { for all } v \in C .
$$

The set of solutions of (1.1) is denoted by $E P(\phi)$. Set $\phi(u, v)=\langle T u, v-u\rangle$, for all $u, v \in C$, where $T: C \rightarrow H$. Then, $w \in E P(\phi)$ if and only if

2010 Mathematics Subject Classification. 47H10; 47H09.

Key words and phrases. Generalized equilibrium problem, constrained convex minimization, averaged mapping, iterative method, variational inequality. 
$\langle T w, v-w\rangle \geq 0$ for all $v \in C$, that is, $w$ is a solution of the variational inequality.

Let $A$ be a bounded operator on $C$. The operator $A$ is strongly positive if there exists a constant $\bar{\gamma}>0$ such that $\langle A x, x\rangle \geq \bar{\gamma}\|x\|^{2}$ for all $x \in C$.

In 2005, Combettes and Hirstoaga [5] introduced an iterative scheme for finding the best approximation to the initial data when $\operatorname{EP}(\phi)$ is nonempty and proved a strong convergence theorem. The equilibrium problem (1.1) includes, as special cases, numerous problems in physics, optimization and economics. Some authors (see $[8,10,11,12,14,18]$ ) have proposed useful methods for solving the equilibrium problem (1.1). Below we describe some of them.

In 2007, Plibtieng and Punpaeng [11] introduced an iterative scheme for finding a common element of the set of solutions of (1.1) and the set of fixed points of a nonexpansive mapping in a Hilbert space as follows:

$$
\begin{cases}\phi\left(u_{n}, y\right)+\frac{1}{r_{n}}\left\langle y-u_{n}, u_{n}-x_{n}\right\rangle \geq 0 & \text { for all } y \in H, \\ x_{n+1}=\alpha_{n} \gamma f\left(x_{n}\right)+\left(I-\alpha_{n} A\right) S u_{n}, & n \geq 1,\end{cases}
$$

where $\phi: H \times H \rightarrow \mathbb{R}$ is a bifunction, $A$ is a strongly positive bounded linear operator on $H, S$ is a nonexpansive mapping of $H$ into itself such that $F(S) \cap$ $E P(\phi) \neq \emptyset, f$ is a contraction, $\gamma>0$ is some constant, $\left\{\alpha_{n}\right\} \subset[0,1]$ and $\left\{r_{n}\right\} \subset(0, \infty)$. Also, they proved the strong convergence of $\left\{x_{n}\right\}$, defined by (1.2) and showed that $\lim _{n \rightarrow \infty} x_{n}$ is the unique solution of a certain variational inequality.

In 2010, Wang et al. [14] introduced the following composite iterative scheme:

$$
\left\{\begin{array}{l}
\phi\left(u_{n}, y\right)+\frac{1}{r_{n}}\left\langle y-u_{n}, u_{n}-x_{n}\right\rangle \geq 0 \quad \text { for all } y \in H, \\
y_{n}=\alpha_{n} \gamma f\left(x_{n}\right)+\left(I-\alpha_{n} A\right) T_{n} u_{n}, \\
x_{n+1}=\left(1-\beta_{n}\right) y_{n}+\beta_{n} T_{n} y_{n}, \quad n \geq 1,
\end{array}\right.
$$

where $\phi: H \times H \rightarrow \mathbb{R}$ is a bifunction, $A$ is a strongly positive bounded linear operator on $H,\left\{T_{n}\right\}$ is a countable family of nonexpansive mappings of $H$ into itself such that $\bigcap_{n=1}^{\infty} F\left(T_{n}\right) \cap E P(\phi) \neq \emptyset, f$ is a contraction, $\gamma>0$ is some constant, $x_{1} \in H,\left\{\alpha_{n}\right\},\left\{\beta_{n}\right\} \subset[0,1]$ and $\left\{r_{n}\right\} \subset(0, \infty)$. Under any of the following conditions:

$\left(H_{1}\right) \sum_{n=1}^{\infty}\left|\alpha_{n+1}-\alpha_{n}\right|<\infty$;

$\left(H_{2}\right) \alpha_{n} \in(0,1]$ for every $n \in \mathbb{N}$ and $\lim _{n \rightarrow \infty} \frac{\alpha_{n}}{\alpha_{n+1}}=1$;

$\left(H_{3}\right)\left|\alpha_{n+1}-\alpha_{n}\right|<o\left(\alpha_{n+1}\right)+\sigma_{n}$ and $\sum_{n=1}^{\infty} \sigma_{n}<\infty$

on the sequence $\left\{\alpha_{n}\right\}$, they proved that $\left\{x_{n}\right\}$ (generated by (1.3)) converges strongly to a point in $\bigcap_{n=1}^{\infty} F\left(T_{n}\right) \cap E P(\phi) \neq \emptyset$.

On the other hand, consider the following constrained convex minimization problem:

$$
\operatorname{minimize}\{g(x): x \in C\},
$$


where $g: C \rightarrow \mathbb{R}$ is a real-valued convex function. The set of solutions of the problem (1.4) is denoted by $U$. It is well known that the gradientprojection algorithm (GPA) plays the important role in solving constrained convex minimization problems. If $g$ is (Fréchet) differentiable, then the GPA generates a sequence $\left\{x_{n}\right\}$ via the following recursive formula:

$$
x_{n+1}=P_{C}\left(x_{n}-\lambda \nabla g\left(x_{n}\right)\right) \text { for all } n \geq 0,
$$

or more generally,

$$
x_{n+1}=P_{C}\left(x_{n}-\lambda_{n} \nabla g\left(x_{n}\right)\right) \text { for all } n \geq 0,
$$

where in both (1.5) and (1.6) the initial guess $x_{0}$ is taken from $C$ arbitrarily and the parameters $\lambda$ or $\lambda_{n}$ are positive real numbers satisfying certain conditions. The convergence of the algorithms (1.5) and (1.6) depends on behavior of the gradient $\nabla g$. As a matter of fact, it is known that if $\nabla g$ is $\alpha$-strongly monotone and $L$-Lipschitzian with constants $\alpha, L>0$ for $0<\lambda<\frac{2 \alpha}{L^{2}}$, then the operator

$$
W:=P_{C}(I-\lambda \nabla g)
$$

is a contraction. Hence the sequence $\left\{x_{n}\right\}$ defined by the algorithm (1.5) converges in norm to the unique minimizer of (1.4). However, if the gradient $\nabla g$ fails to be strongly monotone, the operator $W$ defined by (1.7) need not to be contractive. Consequently, the sequence $\left\{x_{n}\right\}$ generated by the algorithm (1.5) may fail to converge strongly (see [17]). If $\nabla g$ is Lipschitzian, then the algorithms (1.5) and (1.6) can still converge in the weak topology under certain conditions.

In 2011, Xu [17] proposed an explicit operator-oriented approach to the algorithm (1.6), that is, an averaged mapping approach. He gave his averaged mapping approach to the GPA (1.6) and the relaxed gradient-projection algorithm. Moreover, he constructed a counterexample which shows that the algorithm (1.5) does not converge in norm in an infinite-dimensional space and also presented two modifications of GPA which were shown to have strong convergence $[16,15]$.

In 2012, Tian and Liu [13] studied the following implicit and explicit composite iterative schemes by the viscosity approximation method for finding the common solution of an equilibrium problem and a constrained convex minimization problem:

$$
\begin{cases}\phi\left(u_{n}, y\right)+\frac{1}{r_{n}}\left\langle y-u_{n}, u_{n}-x_{n}\right\rangle \geq 0 & \text { for all } y \in C, \\ x_{n}=\alpha_{n} f\left(x_{n}\right)+\left(1-\alpha_{n}\right) T_{n} u_{n}, & n \geq 1,\end{cases}
$$

and

$$
\begin{cases}\phi\left(u_{n}, y\right)+\frac{1}{r_{n}}\left\langle y-u_{n}, u_{n}-x_{n}\right\rangle \geq 0 & \text { for all } y \in C, \\ x_{n+1}=\alpha_{n} f\left(x_{n}\right)+\left(1-\alpha_{n}\right) T_{n} u_{n}, & n \geq 1\end{cases}
$$


where in both (1.8) and (1.9), $\phi: C \times C \rightarrow \mathbb{R}$ is a bifunction, $\nabla g$ is an $L$-Lipschitzian mapping with $L \geq 0$ such that $U \cap E P(\phi) \neq \emptyset, f$ is a contraction, $x_{1} \in C,\left\{\alpha_{n}\right\} \subset(0,1),\left\{r_{n}\right\} \subset(0, \infty), u_{n}=Q_{r_{n}} x_{n}, P_{C}\left(I-\lambda_{n} \nabla g\right)=$ $s_{n} I+\left(1-s_{n}\right) T_{n}, s_{n}=\frac{2-\lambda_{n} L}{4}$ and $\left\{\lambda_{n}\right\} \subset\left(0, \frac{2}{L}\right)$. They proved that the sequences $\left\{x_{n}\right\}$, generated by (1.8) and (1.9), converge strongly to a point in $U \cap E P(\phi)$ under certain conditions.

In this paper, motivated by the above results, we propose an explicit composite iterative scheme for finding the common element of the set of solutions of a generalized equilibrium problem and the solution set of a constrained convex minimization problem. Then, we prove a strong convergence theorem which improves the main result of [13]. In order to do this, we recall the following definition.

A generalized equilibrium problem is to find $z \in C$ such that

$$
\phi(z, y)+\langle A z, y-z\rangle \geq 0 \text { for all } y \in C,
$$

where $\phi: C \times C \rightarrow \mathbb{R}$ is a bifunction and $A: C \rightarrow H$ is a monotone map. The set of such $z \in C$ is denoted by $E P$, i.e.,

$$
E P=\{z \in C: \phi(z, y)+\langle A z, y-z\rangle \geq 0 \text { for all } y \in C\} .
$$

In the case when $A \equiv 0, E P$ is denoted by $E P(\phi)$. Numerous problems in physics, variational inequalities, optimization, minimax problems, the Nash equilibrium problem in noncooperative games and economics reduce to finding a solution of (1.10) (see [9], for instance).

2. Preliminaries. Let $H$ be a real Hilbert space with inner product $\langle\cdot, \cdot\rangle$ and the norm $\|\cdot\|$. Weak and strong convergence are denoted by notation $\rightarrow$ and $\rightarrow$, respectively. In a real Hilbert space $H$,

$$
\|\lambda x+(1-\lambda) y\|^{2}=\lambda\|x\|^{2}+(1-\lambda)\|y\|^{2}-\lambda(1-\lambda)\|x-y\|^{2}
$$

for all $x, y \in H$ and $\lambda \in \mathbb{R}$. Let $C$ be a nonempty closed convex subset of $H$. Then, for any $x \in H$ there exists a unique nearest point in $C$, denoted by $P_{C}(x)$, such that

$$
\left\|x-P_{C}(x)\right\| \leq\|x-y\| \text { for all } y \in C .
$$

$P_{C}$ is called the metric projection of $H$ onto $C$. It is known that $P_{C}$ is nonexpansive. Further, for $x \in H$ and $z \in C$,

$$
z=P_{C}(x) \Leftrightarrow\langle x-z, z-y\rangle \geq 0 \text { for all } y \in C .
$$

Lemma 2.1. Let $H$ be a real Hilbert space. Then for all $x, y \in H$

$$
\|x+y\|^{2} \leq\|x\|^{2}+2\langle y, x+y\rangle .
$$

Lemma $2.2([6])$. Let $H$ be a real Hilbert space, $C$ be a closed convex subset of $H$ and $T: C \rightarrow C$ be a nonexpansive mapping with $F(T) \neq \emptyset$. If $\left\{x_{n}\right\}$ is a sequence in $C$ weakly converging to $x$ and if $\left\{(I-T) x_{n}\right\}$ converges to $y$, then $(I-T) x=y$. 
Lemma 2.3 ([2]). Let $C$ be a nonempty closed convex subset of $H$ and $\phi: C \times C \rightarrow \mathbb{R}$ be a bifunction satisfying the following conditions:

$\left(A_{1}\right) \phi(x, x)=0$ for all $x \in C$;

$\left(A_{2}\right) \phi$ is monotone, i.e., $\phi(x, y)+\phi(y, x) \leq 0$, for all $x, y \in C$;

$\left(A_{3}\right)$ for each $x, y, z \in C$,

$$
\lim _{t \downarrow 0} \phi(t z+(1-t) x, y) \leq \phi(x, y) ;
$$

$\left(A_{4}\right)$ for each $x \in C, y \mapsto \phi(x, y)$ is convex and weakly lower semicontinuous.

Let $r>0$ and $x \in H$. Then, there exists $z \in C$ such that

$$
\phi(z, y)+\frac{1}{r}\langle y-z, z-x\rangle \geq 0 \text { for all } y \in C .
$$

Lemma $2.4([5])$. Assume that $\phi: C \times C \rightarrow \mathbb{R}$ satisfies $\left(A_{1}\right)-\left(A_{4}\right)$. For $r>0$ and $x \in H$ define a mapping $Q_{r}: H \rightarrow C$ as follows:

$$
Q_{r} x=\left\{z \in C: \phi(z, y)+\frac{1}{r}\langle y-z, z-x\rangle \geq 0 \text { for all } y \in C\right\}
$$

for all $x \in H$. Then, the following hold:

(I) $Q_{r}$ is single-valued;

(II) $Q_{r}$ is firmly nonexpansive, i.e., for any $x, y \in H$,

$$
\left\|Q_{r} x-Q_{r} y\right\|^{2} \leq\left\langle Q_{r} x-Q_{r} y, x-y\right\rangle ;
$$

(III) $F\left(Q_{r}\right)=E P(\phi)$;

(IV) $E P(\phi)$ is closed and convex.

Definition 2.5. A mapping $T: H \rightarrow H$ is said to be firmly nonexpansive if and only if $2 T-I$ is nonexpansive, or equivalently,

$$
\langle x-y, T x-T y\rangle \geq\|T x-T y\|^{2} \text { for all } x, y \in H .
$$

Alternatively, $T$ is firmly nonexpansive if and only if $T$ can be expressed as

$$
T=\frac{1}{2}(I+S)
$$

where $S: H \rightarrow H$ is nonexpansive. Obviously, projections are firmly nonexpansive.

Definition 2.6 ([13]). A mapping $T: H \rightarrow H$ is said to be an averaged mapping if it can be written as the average of the identity $I$ and a nonexpansive mapping, that is,

$$
T=(1-\alpha) I+\alpha S
$$

where $\alpha \in(0,1)$ and $S: H \rightarrow H$ is nonexpansive. More precisely, when (2.1) holds, we say that $T$ is $\alpha$-averaged.

Clearly, a firmly nonexpansive mapping is a $\frac{1}{2}$-averaged map. 
Proposition 2.7 ([4]). Let operators $S, T, V: H \rightarrow H$ be given.

(I) If $T=(1-\alpha) S+\alpha V$ for some $\alpha \in(0,1), S$ is averaged and $V$ is nonexpansive, then $T$ is averaged.

(II) $T$ is firmly nonexpansive if and only if the complement $I-T$ is firmly nonexpansive.

(III) If $T=(1-\alpha) S+\alpha V$ for some $\alpha \in(0,1), S$ is firmly nonexpansive and $V$ is nonexpansive, then $T$ is averaged.

(IV) The composite of finitely many averaged mapping is averaged. That is, if each of the mappings $\left\{T_{i}\right\}_{i=1}^{N}$ is averaged, then so is the composite $T_{1} \ldots T_{N}$. In particular, if $T_{1}$ is $\alpha_{1}$-averaged, and $T_{2}$ is $\alpha_{2}$-averaged, where $\alpha_{1}, \alpha_{2} \in(0,1)$, then the composite $T_{1} T_{2}$ is $\alpha$-averaged, where $\alpha=\alpha_{1}+\alpha_{2}-\alpha_{1} \alpha_{2}$.

Definition 2.8. A nonlinear operator $G$ with the domain $D(G) \subseteq H$ and the range $R(G) \subseteq H$ is said to be:

(a) monotone if

$$
\langle x-y, G x-G y\rangle \geq 0 \text { for all } x, y \in D(G),
$$

(b) $\nu$-inverse strongly monotone (for short, $\nu$-ism), where $\nu>0$, if

$$
\langle x-y, G x-G y\rangle \geq \nu\|G x-G y\|^{2} \text { for all } x, y \in D(G) .
$$

It can be easily seen that if $G$ is nonexpansive, then $I-G$ is monotone and the projection map $P_{C}$ is 1-ism.

The inverse strongly monotone (also referred to as co-coercive) operators have been widely used to solve practical problems in various fields, for instance, in traffic assignment problems, see for example, $[3,7]$ and references therein.

Proposition 2.9 ([4]). Let $T$ be an operator of $H$ into itself.

(a) $T$ is nonexpansive if and only if the complement $I-T$ is $\frac{1}{2}$-ism.

(b) If $T$ is $\nu$-ism, then for $\gamma>0, \gamma T$ is $\frac{\nu}{\gamma}$-ism.

(c) $T$ is averaged if and only if the complement $I-T$ is $\nu$-ism for some $\nu>\frac{1}{2}$. Indeed, for $\alpha \in(0,1), T$ is $\alpha$-averaged if and only if $I-T$ is $\frac{1}{2 \alpha}-i s m$.

Lemma 2.10 ([1]). Assume that $\left\{a_{n}\right\}$ is a sequence of nonnegative real numbers such that

$$
a_{n+1} \leq\left(1-\gamma_{n}\right) a_{n}+\gamma_{n} v_{n}+\mu_{n},
$$

where $\left\{\gamma_{n}\right\}$ is a sequence in $[0,1],\left\{\mu_{n}\right\}$ is a sequence of nonnegative real numbers and $\left\{v_{n}\right\}$ is a sequence in $\mathbb{R}$ such that

(I) $\sum_{n=1}^{\infty} \gamma_{n}=\infty$;

(II) $\lim \sup _{n \rightarrow \infty} v_{n} \leq 0$;

(III) $\sum_{n=1}^{\infty} \mu_{n}<\infty$.

Then $\lim _{n \rightarrow \infty} a_{n}=0$. 
3. Main result. In this paper, we always assume that $g: C \rightarrow \mathbb{R}$ is a realvalued convex function and $\nabla g$ is an $L$-Lipschitzian mapping with $L \geq 0$. We observe that $x^{*} \in C$ solves the minimization problem (1.4) if and only if $x^{*} \in C$ solves the fixed point equation

$$
x^{*}=P_{C}(I-\lambda \nabla g) x^{*},
$$

where $\lambda>0$ is any fixed positive number. Since the Lipschitz continuity of $\nabla g$ implies that it is indeed inverse strongly monotone, its complement can be an averaged mapping. Consequently, the GPA can be written as the composite of a projection and an averaged mapping, which is again an averaged mapping. This shows that the averaged mapping plays the important role in the gradient-projection algorithm.

Note that $\nabla g$ is $L$-Lipschitzian. This implies $\nabla g$ is $\frac{1}{L}$-ism, which then implies $\lambda \nabla g$ is $\frac{1}{\lambda L}$-ism. So, by Proposition 2.9, $I-\lambda \nabla g$ is $\frac{\lambda L}{2}$-averaged. Since the projection $P_{C}$ is $\frac{1}{2}$-averaged, we see from Proposition 2.7 that the composite $P_{C}(I-\lambda \nabla g)$ is $\left(\frac{2+\lambda L}{4}\right)$-averaged for $0<\lambda<\frac{2}{L}$. Hence, $P_{C}\left(I-\lambda_{n} \nabla g\right)$ is $\left(\frac{2+\lambda_{n} L}{4}\right)$-averaged for each $n \in \mathbb{N}$. Therefore, we can write

$$
P_{C}\left(I-\lambda_{n} \nabla g\right)=\frac{2-\lambda_{n} L}{4} I+\frac{2+\lambda_{n} L}{4} T_{n}=s_{n} I+\left(1-s_{n}\right) T_{n},
$$

where $T_{n}$ is nonexpansive and $s_{n}=\frac{2-\lambda_{n} L}{4}$.

Now, we introduce an explicit iterative scheme for finding a common element of the set of solutions of the generalized equilibrium problem (1.10) and the solution set of the constrained convex minimization problem (1.4). Then, we prove a strong convergence theorem. Before, two lemmas are proved.

Lemma 3.1. Suppose $C$ is a nonempty closed convex subset of a real Hilbert space $H, A$ is an $\alpha$-inverse-strongly monotone map on $C$ and $0<r<2 \alpha$. Then $I-r A$ is nonexpansive.

Proof. For $x, y \in C$,

$$
\begin{aligned}
\|(I-r A) x-(I-r A) y\|^{2} & =\|x-y-r(A x-A y)\|^{2} \\
& =\|x-y\|^{2}-2 r\langle x-y, A x-A y\rangle+r^{2}\|A x-A y\|^{2} \\
& \leq\|x-y\|^{2}-2 \alpha r\|A x-A y\|^{2}+r^{2}\|A x-A y\|^{2} \\
& =\|x-y\|^{2}+r(r-2 \alpha)\|A x-A y\|^{2} \\
& \leq\|x-y\|^{2} .
\end{aligned}
$$

Thus $I-r A$ is nonexpansive.

Lemma 3.2. Let $C$ be a nonempty closed convex subset of a real Hilbert space $H$. Let $\phi: C \times C \rightarrow \mathbb{R}$ be a bifunction satisfying the conditions $\left(A_{1}\right)-\left(A_{4}\right)$ (of Lemma 2.3) and $A$ be an $\alpha$-inverse-strongly monotone map. 
Suppose $\left\{x_{n}\right\}$ is a bounded sequence in $C$ and $\left\{r_{n}\right\} \subset[a, b] \subset(0,2 \alpha)$ is a real sequence. If $u_{n}=Q_{r_{n}}\left(x_{n}-r_{n} A x_{n}\right)$, then

$$
\left\|u_{n+1}-u_{n}\right\| \leq\left\|x_{n+1}-x_{n}\right\|+\left|r_{n}-r_{n+1}\right| M_{1},
$$

where $M_{1}=\sup \left\{\left\|A x_{n}\right\|+\frac{1}{a}\left\|u_{n+1}-k_{n+1}\right\|: n \in \mathbb{N}\right\}$.

Proof. Let $p \in E P$. Then $\phi(p, y)+\langle A p, y-p\rangle \geq 0$, for all $y \in C$. So

$$
\phi(p, y)+\frac{1}{r_{n}}\left\langle p-\left(p-r_{n} A p\right), y-p\right\rangle \geq 0
$$

for all $y \in C$. Therefore, by Lemma 3.1,

(3.1) $\left\|u_{n}-p\right\|=\left\|Q_{r_{n}}\left(I-r_{n} A\right) x_{n}-Q_{r_{n}}\left(I-r_{n} A\right) p\right\| \leq\left\|x_{n}-p\right\|, \quad n \geq 1$.

Consequently, $\left\{u_{n}\right\}$ is a bounded sequence. Set $k_{n}=x_{n}-r_{n} A x_{n}$, then $u_{n}=Q_{r_{n}} k_{n}$ and $u_{n+1}=Q_{r_{n+1}} k_{n+1}$. So

$$
\phi\left(u_{n}, y\right)+\frac{1}{r_{n}}\left\langle y-u_{n}, u_{n}-k_{n}\right\rangle \geq 0 \text { for all } y \in C
$$

and

$$
\phi\left(u_{n+1}, y\right)+\frac{1}{r_{n+1}}\left\langle y-u_{n+1}, u_{n+1}-k_{n+1}\right\rangle \geq 0 \text { for all } y \in C .
$$

Set $y=u_{n+1}$ in (3.2) and $y=u_{n}$ in (3.3), then by adding these last two inequalities and using condition $\left(A_{2}\right)$, we obtain

$$
\left\langle u_{n+1}-u_{n}, \frac{u_{n}-k_{n}}{r_{n}}-\frac{u_{n+1}-k_{n+1}}{r_{n+1}}\right\rangle \geq 0
$$

and hence

$$
\left\langle u_{n+1}-u_{n}, u_{n}-u_{n+1}+u_{n+1}-k_{n}-\frac{r_{n}}{r_{n+1}}\left(u_{n+1}-k_{n+1}\right)\right\rangle \geq 0 .
$$

This implies that

$$
\begin{aligned}
\left\|u_{n+1}-u_{n}\right\|^{2} & \leq\left\langle u_{n+1}-u_{n}, k_{n+1}-k_{n}+\left(1-\frac{r_{n}}{r_{n+1}}\right)\left(u_{n+1}-k_{n+1}\right)\right\rangle \\
& \leq\left\|u_{n+1}-u_{n}\right\|\left\{\left\|k_{n+1}-k_{n}\right\|+\frac{1}{a}\left|r_{n}-r_{n+1}\right|\left\|u_{n+1}-k_{n+1}\right\|\right\} .
\end{aligned}
$$

Therefore,

$$
\begin{aligned}
\left\|u_{n+1}-u_{n}\right\| \leq & \left\|k_{n+1}-k_{n}\right\|+\frac{1}{a}\left|r_{n}-r_{n+1}\right|\left\|u_{n+1}-k_{n+1}\right\| \\
= & \left\|x_{n+1}-r_{n+1} A x_{n+1}-\left(x_{n}-r_{n} A x_{n}\right)\right\| \\
& +\frac{1}{a}\left|r_{n}-r_{n+1}\right|\left\|u_{n+1}-k_{n+1}\right\| \\
\leq & \left\|x_{n+1}-r_{n+1} A x_{n+1}-\left(x_{n}-r_{n+1} A x_{n}\right)\right\|+\left|r_{n}-r_{n+1}\right|\left\|A x_{n}\right\| \\
& +\frac{1}{a}\left|r_{n}-r_{n+1}\right|\left\|u_{n+1}-k_{n+1}\right\| \\
\leq & \left\|x_{n+1}-x_{n}\right\|+\left|r_{n}-r_{n+1}\right| M_{1},
\end{aligned}
$$


where $M_{1}=\sup \left\{\left\|A x_{n}\right\|+\frac{1}{a}\left\|u_{n+1}-k_{n+1}\right\|: n \in \mathbb{N}\right\}$.

Theorem 3.3. Let $C$ be a nonempty closed convex subset of a real Hilbert space $H, \phi: C \times C \rightarrow \mathbb{R}$ be a bifunction satisfying the conditions $\left(A_{1}\right)-\left(A_{4}\right)$ (of Lemma 2.3), $g: C \rightarrow \mathbb{R}$ be a real-valued convex function and $\nabla g$ be an $L$-Lipschitzian mapping with $L \geq 0$ such that $U \cap E P \neq \emptyset$. Let $f$ be a contraction of $C$ into itself with the constant $k$ and $A$ be an $\alpha$-ism map. Suppose $\left\{\alpha_{n}\right\},\left\{\beta_{n}\right\}$ and $\left\{r_{n}\right\}$ are real sequences satisfying the following conditions:

$\left(B_{1}\right)\left\{\alpha_{n}\right\} \subset[0,1], \lim _{n \rightarrow \infty} \alpha_{n}=0$ and $\sum_{n=1}^{\infty} \alpha_{n}=\infty ;$

$\left(B_{2}\right)\left\{r_{n}\right\} \subset[a, b] \subset(0,2 \alpha)$ and $\sum_{n=1}^{\infty}\left|r_{n+1}-r_{n}\right|<\infty$.

Let $\left\{x_{n}\right\}$ be a sequence generated by

$$
\left\{\begin{array}{l}
\phi\left(u_{n}, y\right)+\frac{1}{r_{n}}\left\langle y-u_{n}, u_{n}-x_{n}\right\rangle+\left\langle A x_{n}, y-u_{n}\right\rangle \geq 0 \text { for all } y \in C, \\
x_{n+1}=\alpha_{n} f\left(x_{n}\right)+\left(1-\alpha_{n}\right) T_{n} u_{n},
\end{array}\right.
$$

where $x_{1} \in C,\left\{\lambda_{n}\right\} \subset\left(0, \frac{2}{L}\right), u_{n}=Q_{r_{n}}\left(x_{n}-r_{n} A x_{n}\right), P_{C}\left(I-\lambda_{n} \nabla g\right)=$ $s_{n} I+\left(1-s_{n}\right) T_{n}$ and $s_{n}=\frac{2-\lambda_{n} L}{4}$. Assume that $\lim _{n \rightarrow \infty} s_{n}=0$ and $\sum_{n=1}^{\infty}\left|s_{n+1}-s_{n}\right|<\infty$. Then, under any of the three conditions $\left(H_{1}\right)$, $\left(H_{2}\right)$ and $\left(H_{3}\right)$ on the sequence $\left\{\alpha_{n}\right\}$, the sequences $\left\{x_{n}\right\}$ and $\left\{u_{n}\right\}$ defined by (3.4) converge strongly to $q \in U \cap E P$, where $q=P_{U \cap E P} f(q)$, which solves the following variational inequality:

$$
\langle(I-f) q, q-x\rangle \leq 0 \text { for all } x \in U \cap E P .
$$

Proof. Since $P_{U \cap E P} f$ is a contraction of $C$ into itself, there exists a unique element $q \in C$ such that $q=P_{U \cap E P} f(q)$. Using condition $\left(B_{1}\right)$, without loss of generality, we may assume that $\alpha_{n} \leq\|A\|^{-1}$. Now, we proceed with the following steps:

Step 1. First, we claim that $\left\{x_{n}\right\}$ and $\left\{u_{n}\right\}$ are bounded. Let $p \in U \cap E P$. Then, using the equality $T_{n} p=p,(3.1)$ and (3.4), we obtain

$$
\begin{aligned}
\left\|x_{n+1}-p\right\| & =\left\|\alpha_{n}\left(f\left(x_{n}\right)-p\right)+\left(1-\alpha_{n}\right)\left(T_{n} u_{n}-p\right)\right\| \\
& \leq\left(1-\alpha_{n}\right)\left\|u_{n}-p\right\|+\alpha_{n}\left\|f\left(x_{n}\right)-f(p)\right\|+\alpha_{n}\|f(p)-p\| \\
& \leq\left(1-\alpha_{n}\right)\left\|x_{n}-p\right\|+\alpha_{n} k\left\|x_{n}-p\right\|+\alpha_{n}\|f(p)-p\| \\
& \leq\left(1-\alpha_{n}(1-k)\right)\left\|x_{n}-p\right\|+\alpha_{n}(1-k) \frac{\|f(p)-p\|}{1-k} \\
& \leq \max \left\{\left\|x_{n}-p\right\|, \frac{\|f(p)-p\|}{1-k}\right\} .
\end{aligned}
$$

By induction,

$$
\left\|x_{n}-p\right\| \leq \max \left\{\left\|x_{1}-p\right\|, \frac{1}{1-k}\|f(p)-p\|\right\} \text { for all } n \geq 1 .
$$

Hence, $\left\{x_{n}\right\}$ is bounded, so are $\left\{u_{n}\right\},\left\{f\left(x_{n}\right)\right\}$ and $\left\{T_{n} u_{n}\right\}$. 
Step 2. We claim that $\lim _{n \rightarrow \infty}\left\|x_{n+1}-x_{n}\right\|=0$. Set

$$
M_{2}=\sup \left\{\left\|f\left(x_{n}\right)\right\|,\left\|T_{n} u_{n}\right\|: n \in \mathbb{N}\right\} .
$$

From (3.4) we get

$$
\begin{aligned}
\| x_{n+2}- & x_{n+1} \| \\
= & \| \alpha_{n+1} f\left(x_{n+1}\right)+\left(1-\alpha_{n+1}\right) T_{n+1} u_{n+1}-\alpha_{n} f\left(x_{n}\right) \\
& -\left(1-\alpha_{n}\right) T_{n} u_{n} \| \\
= & \|\left(1-\alpha_{n+1}\right)\left(T_{n+1} u_{n+1}-T_{n} u_{n}\right)-\left(\alpha_{n+1}-\alpha_{n}\right) T_{n} u_{n} \\
& +\alpha_{n+1}\left(f\left(x_{n+1}\right)-f\left(x_{n}\right)\right)+\left(\alpha_{n+1}-\alpha_{n}\right) f\left(x_{n}\right) \| \\
\leq & \left(1-\alpha_{n+1}\right)\left\|T_{n+1} u_{n+1}-T_{n} u_{n}\right\|+\left|\alpha_{n+1}-\alpha_{n}\right|\left\|T_{n} u_{n}\right\| \\
& +\alpha_{n+1} k\left\|x_{n+1}-x_{n}\right\|+\left|\alpha_{n+1}-\alpha_{n}\right|\left\|f\left(x_{n}\right)\right\| \\
\leq & \left(1-\alpha_{n+1}\right)\left(\left\|T_{n+1} u_{n+1}-T_{n+1} u_{n}\right\|+\left\|T_{n+1} u_{n}-T_{n} u_{n}\right\|\right) \\
& +\left|\alpha_{n+1}-\alpha_{n}\right| M_{2}+\alpha_{n+1} k\left\|x_{n+1}-x_{n}\right\|+\left|\alpha_{n+1}-\alpha_{n}\right| M_{2} \\
\leq & \left(1-\alpha_{n+1}\right)\left\|u_{n+1}-u_{n}\right\|+2 M_{2}\left|\alpha_{n+1}-\alpha_{n}\right| \\
& +\alpha_{n+1} k\left\|x_{n+1}-x_{n}\right\|+\left\|T_{n+1} u_{n}-T_{n} u_{n}\right\|
\end{aligned}
$$

for all $n \in \mathbb{N}$. From Lemma 3.2 we obtain

$$
\left\|u_{n+1}-u_{n}\right\| \leq\left\|x_{n+1}-x_{n}\right\|+\left|r_{n}-r_{n+1}\right| M_{1},
$$

where $M_{1}=\sup \left\{\left\|A x_{n}\right\|+\frac{1}{a}\left\|u_{n}-x_{n}\right\|: n \in \mathbb{N}\right\}$. Substituting (3.6) in (3.5), we have

$$
\begin{aligned}
& \left\|x_{n+2}-x_{n+1}\right\| \leq\left(1-\alpha_{n+1}\right)\left\{\left\|x_{n+1}-x_{n}\right\|+\left|r_{n}-r_{n+1}\right| M_{1}\right\} \\
& \quad+2 M_{2}\left|\alpha_{n+1}-\alpha_{n}\right|+\alpha_{n+1} k\left\|x_{n+1}-x_{n}\right\|+\left\|T_{n+1} u_{n}-T_{n} u_{n}\right\| \\
& \quad \leq\left[1-\alpha_{n+1}(1-k)\right]\left\|x_{n+1}-x_{n}\right\|+\left|r_{n}-r_{n+1}\right| M_{1} \\
& \quad+2 M_{2}\left|\alpha_{n+1}-\alpha_{n}\right|+\left\|T_{n+1} u_{n}-T_{n} u_{n}\right\| \\
& \quad \leq\left[1-\alpha_{n+1}(1-k)\right]\left\|x_{n+1}-x_{n}\right\|+M_{3}\left(\left|r_{n}-r_{n+1}\right|+\left|\alpha_{n+1}-\alpha_{n}\right|\right) \\
& \quad+\left\|T_{n+1} u_{n}-T_{n} u_{n}\right\|,
\end{aligned}
$$

where $M_{3}=\max \left\{M_{1}, 2 M_{2}\right\}$.

On the other hand, since $\nabla g$ is $\frac{1}{L}$-ism, $P_{C}\left(I-\lambda_{n+1} \nabla g\right)$ is nonexpansive. It follows that for any given $p \in U$,

$$
\begin{aligned}
\left\|P_{C}\left(I-\lambda_{n+1} \nabla g\right) u_{n}\right\| & \leq\left\|P_{C}\left(I-\lambda_{n+1} \nabla g\right) u_{n}-p\right\|+\|p\| \\
& \leq\left\|P_{C}\left(I-\lambda_{n+1} \nabla g\right) u_{n}-P_{C}\left(I-\lambda_{n+1} \nabla g\right) p\right\|+\|p\| \\
& \leq\left\|u_{n}-p\right\|+\|p\| \\
& \leq\left\|u_{n}\right\|+2\|p\| .
\end{aligned}
$$


This implies that $\left\{P_{C}\left(I-\lambda_{n+1} \nabla g\right) u_{n}\right\}$ is bounded. Also, observe that

$$
\begin{aligned}
& \left\|T_{n+1} u_{n}-T_{n} u_{n}\right\| \\
& =\| \frac{4 P_{C}\left(I-\lambda_{n+1} \nabla g\right)-\left(2-\lambda_{n+1} L\right) I}{2+\lambda_{n+1} L} u_{n} \\
& -\frac{4 P_{C}\left(I-\lambda_{n} \nabla g\right)-\left(2-\lambda_{n} L\right) I}{2+\lambda_{n} L} u_{n} \| \\
& \leq\left\|\frac{4 P_{C}\left(I-\lambda_{n+1} \nabla g\right)}{2+\lambda_{n+1} L} u_{n}-\frac{4 P_{C}\left(I-\lambda_{n} \nabla g\right)}{2+\lambda_{n} L} u_{n}\right\| \\
& +\left\|\frac{2-\lambda_{n+1} L}{2+\lambda_{n+1} L} u_{n}-\frac{2-\lambda_{n} L}{2+\lambda_{n} L} u_{n}\right\| \\
& =\left\|\frac{4\left(2+\lambda_{n} L\right) P_{C}\left(I-\lambda_{n+1} \nabla g\right) u_{n}-4\left(2+\lambda_{n+1}\right) P_{C}\left(I-\lambda_{n} \nabla g\right) u_{n}}{\left(2+\lambda_{n+1} L\right)\left(2+\lambda_{n} L\right)}\right\| \\
& +\frac{4 L\left|\lambda_{n+1}-\lambda_{n}\right|}{\left(2+\lambda_{n+1} L\right)\left(2+\lambda_{n} L\right)}\left\|u_{n}\right\| \\
& \leq \| \frac{4 L\left(\lambda_{n}-\lambda_{n+1}\right) P_{C}\left(I-\lambda_{n+1} \nabla g\right) u_{n}}{\left(2+\lambda_{n+1} L\right)\left(2+\lambda_{n} L\right)} \\
& +\frac{4\left(2+\lambda_{n+1} L\right)\left(P_{C}\left(I-\lambda_{n+1} \nabla g\right)-P_{C}\left(I-\lambda_{n} \nabla g\right)\right) u_{n}}{\left(2+\lambda_{n+1} L\right)\left(2+\lambda_{n} L\right)} \| \\
& +\frac{4 L\left|\lambda_{n+1}-\lambda_{n}\right|}{\left(2+\lambda_{n+1} L\right)\left(2+\lambda_{n} L\right)}\left\|u_{n}\right\| \\
& \leq \frac{4 L\left|\lambda_{n}-\lambda_{n+1}\right|\left\|P_{C}\left(I-\lambda_{n+1} \nabla g\right) u_{n}\right\|}{\left(2+\lambda_{n+1} L\right)\left(2+\lambda_{n} L\right)} \\
& +\frac{4\left(2+\lambda_{n+1} L\right)\left\|P_{C}\left(I-\lambda_{n+1} \nabla g\right) u_{n}-P_{C}\left(I-\lambda_{n} \nabla g\right) u_{n}\right\|}{\left(2+\lambda_{n+1} L\right)\left(2+\lambda_{n} L\right)} \\
& +\frac{4 L\left|\lambda_{n+1}-\lambda_{n}\right|}{\left(2+\lambda_{n+1} L\right)\left(2+\lambda_{n} L\right)}\left\|u_{n}\right\| \\
& \leq\left|\lambda_{n+1}-\lambda_{n}\right|\left[L\left\|P_{C}\left(I-\lambda_{n+1} \nabla g\right) u_{n}\right\|+4\left\|\nabla g\left(u_{n}\right)\right\|+L\left\|u_{n}\right\|\right] \\
& \leq M_{4}\left|\lambda_{n+1}-\lambda_{n}\right| \text {, }
\end{aligned}
$$

where $M_{4}=\max \left\{L\left\|P_{C}\left(I-\lambda_{n+1} \nabla g\right) u_{n}\right\|+4\left\|\nabla g\left(u_{n}\right)\right\|+L\left\|u_{n}\right\|: n \in \mathbb{N}\right\}$. Thus, substituting (3.8) in (3.7), we have

$$
\begin{aligned}
\left\|x_{n+2}-x_{n+1}\right\| \leq & {\left[1-\alpha_{n+1}(1-k)\right]\left\|x_{n+1}-x_{n}\right\| } \\
& +M\left(\left|r_{n}-r_{n+1}\right|+\left|\alpha_{n+1}-\alpha_{n}\right|+\left|\lambda_{n+1}-\lambda_{n}\right|\right),
\end{aligned}
$$

where $M=\max \left\{M_{3}, M_{4}\right\}$.

Now, we show that under any of the three conditions $\left(H_{1}\right)-\left(H_{3}\right)$, we have

$$
\lim _{n \rightarrow \infty}\left\|x_{n+1}-x_{n}\right\|=0 .
$$


Let $\left(H_{1}\right)$ hold. Set $\mu_{n}=M\left(\left|r_{n}-r_{n+1}\right|+\left|\alpha_{n+1}-\alpha_{n}\right|+\left|\lambda_{n+1}-\lambda_{n}\right|\right)$, then

$$
\sum_{n=1}^{\infty} \mu_{n}=M \sum_{n=1}^{\infty}\left(\left|r_{n}-r_{n+1}\right|+\left|\alpha_{n+1}-\alpha_{n}\right|+\left|\lambda_{n+1}-\lambda_{n}\right|\right)<\infty .
$$

Therefore, by Lemma 2.10, $\lim _{n \rightarrow \infty}\left\|x_{n+1}-x_{n}\right\|=0$.

If $\left(H_{2}\right)$ holds, then from (3.9) we obtain

$$
\begin{aligned}
\left\|x_{n+2}-x_{n+1}\right\| \leq & {\left[1-\alpha_{n+1}(1-k)\right]\left\|x_{n+1}-x_{n}\right\|+\alpha_{n+1} M\left|1-\frac{\alpha_{n}}{\alpha_{n+1}}\right| } \\
& +M\left(\left|r_{n+1}-r_{n}\right|+\left|\lambda_{n+1}-\lambda_{n}\right|\right) .
\end{aligned}
$$

Set $\mu_{n}=M\left(\left|r_{n+1}-r_{n}\right|+\left|\lambda_{n+1}-\lambda_{n}\right|\right)$, then

$$
\sum_{n=1}^{\infty} \mu_{n}=M \sum_{n=1}^{\infty}\left(\left|r_{n+1}-r_{n}\right|+\left|\lambda_{n+1}-\lambda_{n}\right|\right)<\infty .
$$

Therefore, by Lemma $2.10, \lim _{n \rightarrow \infty}\left\|x_{n+1}-x_{n}\right\|=0$.

If $\left(H_{3}\right)$ holds, then from (3.9) we get

$$
\begin{aligned}
\left\|x_{n+2}-x_{n+1}\right\| \leq & {\left[1-\alpha_{n+1}(1-k)\right]\left\|x_{n+1}-x_{n}\right\|+M o\left(\alpha_{n+1}\right) } \\
& +M\left(\sigma_{n}+\left|r_{n+1}-r_{n}\right|+\left|\lambda_{n+1}-\lambda_{n}\right|\right) .
\end{aligned}
$$

Set $\mu_{n}=M\left(\sigma_{n}+\left|r_{n+1}-r_{n}\right|+\left|\lambda_{n+1}-\lambda_{n}\right|\right)$, then

$$
\sum_{n=1}^{\infty} \mu_{n}=M_{2} \sum_{n=1}^{\infty}\left(\sigma_{n}+\left|r_{n+1}-r_{n}\right|+\left|\lambda_{n+1}-\lambda_{n}\right|\right)<\infty .
$$

Therefore, by Lemma 2.10, $\lim _{n \rightarrow \infty}\left\|x_{n+1}-x_{n}\right\|=0$.

Step 3. We claim that $\lim _{n \rightarrow \infty}\left\|x_{n}-u_{n}\right\|=0$ and

$$
\lim _{n \rightarrow \infty}\left\|P_{C}\left(I-\frac{2}{L} \nabla g\right) u_{n}-u_{n}\right\|=0 .
$$

To this end, let $p \in U \cap E P$. Then

$$
\begin{aligned}
\left\|u_{n}-p\right\|^{2} & =\left\|Q_{r_{n}}\left(x_{n}-r_{n} A x_{n}\right)-Q_{r_{n}}\left(p-r_{n} A p\right)\right\|^{2} \\
& \leq\left\|x_{n}-r_{n} A x_{n}-p+r_{n} A p\right\|^{2} \\
& =\left\|x_{n}-p\right\|^{2}+r_{n}^{2}\left\|A x_{n}-A p\right\|^{2}-2 r_{n}\left\langle x_{n}-p, A x_{n}-A p\right\rangle \\
& \leq\left\|x_{n}-p\right\|^{2}+r_{n}\left(r_{n}-2 \alpha\right)\left\|A x_{n}-A p\right\|^{2} .
\end{aligned}
$$


Therefore

$$
\begin{aligned}
\left\|x_{n+1}-p\right\|^{2}= & \left\|\alpha_{n} f\left(x_{n}\right)+\left(1-\alpha_{n}\right) T_{n} u_{n}-p\right\|^{2} \\
= & \left\|\alpha_{n}\left(f\left(x_{n}\right)-T_{n} u_{n}\right)+T_{n} u_{n}-p\right\|^{2} \\
= & \alpha_{n}^{2}\left\|f\left(x_{n}\right)-T_{n} u_{n}\right\|^{2}+\left\|T_{n} u_{n}-p\right\|^{2} \\
& +2 \alpha_{n}\left\langle f\left(x_{n}\right)-T_{n} u_{n}, T_{n} u_{n}-p\right\rangle \\
\leq & \alpha_{n}^{2}\left\|f\left(x_{n}\right)-T_{n} u_{n}\right\|^{2}+\left\|u_{n}-p\right\|^{2} \\
& +2 \alpha_{n}\left\langle f\left(x_{n}\right)-T_{n} u_{n}, T_{n} u_{n}-p\right\rangle \\
\leq & \alpha_{n}^{2}\left\|f\left(x_{n}\right)-T_{n} u_{n}\right\|^{2}+\left\|x_{n}-p\right\|^{2} \\
& +r_{n}\left(r_{n}-2 \alpha\right)\left\|A x_{n}-A p\right\|^{2} \\
& +2 \alpha_{n}\left\|f\left(x_{n}\right)-T_{n} u_{n}\right\|\left\|u_{n}-p\right\| .
\end{aligned}
$$

This implies that

$$
\begin{aligned}
r_{n}\left(2 \alpha-r_{n}\right)\left\|A x_{n}-A p\right\|^{2} \leq & \left\|x_{n}-p\right\|^{2}-\left\|x_{n+1}-p\right\|^{2}+\alpha_{n}^{2}\left\|f\left(x_{n}\right)-T_{n} u_{n}\right\|^{2} \\
& +2 \alpha_{n}\left\|f\left(x_{n}\right)-T_{n} u_{n}\right\|\left\|u_{n}-p\right\| \\
\leq & \left(\left\|x_{n}-p\right\|+\left\|x_{n+1}-p\right\|\right)\left\|x_{n+1}-x_{n}\right\| \\
& +\alpha_{n}^{2}\left\|f\left(x_{n}\right)-T_{n} u_{n}\right\|^{2} \\
& +2 \alpha_{n}\left\|f\left(x_{n}\right)-T_{n} u_{n}\right\|\left\|u_{n}-p\right\| .
\end{aligned}
$$

From $\left(B_{1}\right),\left(B_{2}\right)$ and Step 2 we obtain

$$
\lim _{n \rightarrow \infty}\left\|A x_{n}-A p\right\|=0
$$

Also, from (II) in Lemma 2.4 and Lemma 3.1 we get

$$
\begin{aligned}
\left\|u_{n}-p\right\|^{2}= & \left\|Q_{r_{n}}\left(x_{n}-r_{n} A x_{n}\right)-Q_{r_{n}}\left(p-r_{n} A p\right)\right\|^{2} \\
\leq & \left\langle x_{n}-r_{n} A x_{n}-\left(p-r_{n} A p\right), u_{n}-p\right\rangle \\
= & \frac{1}{2}\left\{\left\|x_{n}-r_{n} A x_{n}-\left(p-r_{n} A p\right)\right\|^{2}+\left\|u_{n}-p\right\|^{2}\right. \\
& \left.\quad-\left\|x_{n}-r_{n} A x_{n}-\left(p-r_{n} A p\right)-\left(u_{n}-p\right)\right\|^{2}\right\} \\
\leq & \frac{1}{2}\left\{\left\|x_{n}-p\right\|^{2}+\left\|u_{n}-p\right\|^{2}\right. \\
& \left.\quad-\left\|x_{n}-u_{n}-r_{n}\left(A x_{n}-A p\right)\right\|^{2}\right\} \\
= & \frac{1}{2}\left\{\left\|x_{n}-p\right\|^{2}+\left\|u_{n}-p\right\|^{2}-\left\|x_{n}-u_{n}\right\|^{2}\right. \\
& \left.\quad+2 r_{n}\left\langle x_{n}-u_{n}, A x_{n}-A p\right\rangle-r_{n}^{2}\left\|A x_{n}-A p\right\|^{2}\right\} .
\end{aligned}
$$


This implies that

$$
\begin{aligned}
\left\|u_{n}-p\right\|^{2} \leq & \left\|x_{n}-p\right\|^{2}-\left\|x_{n}-u_{n}\right\|^{2}+2 r_{n}\left\langle x_{n}-u_{n}, A x_{n}-A p\right\rangle \\
& -r_{n}^{2}\left\|A x_{n}-A p\right\|^{2} \\
& \leq\left\|x_{n}-p\right\|^{2}-\left\|x_{n}-u_{n}\right\|^{2}+2 r_{n}\left\langle x_{n}-u_{n}, A x_{n}-A p\right\rangle \\
& \leq\left\|x_{n}-p\right\|^{2}-\left\|x_{n}-u_{n}\right\|^{2}+2 r_{n}\left\|x_{n}-u_{n}\right\|\left\|A x_{n}-A p\right\| .
\end{aligned}
$$

By the same argument in (3.11),

$$
\begin{aligned}
\left\|x_{n+1}-p\right\|^{2} \leq & \alpha_{n}^{2}\left\|f\left(x_{n}\right)-T_{n} u_{n}\right\|^{2}+\left\|u_{n}-p\right\|^{2} \\
& +2 \alpha_{n}\left\langle f\left(x_{n}\right)-T_{n} u_{n}, T_{n} u_{n}-p\right\rangle \\
\leq & \alpha_{n}^{2}\left\|f\left(x_{n}\right)-T_{n} u_{n}\right\|^{2}+\left\|x_{n}-p\right\|^{2}-\left\|x_{n}-u_{n}\right\|^{2} \\
& +2 r_{n}\left\|x_{n}-u_{n}\right\|\left\|A x_{n}-A p\right\|+2 \alpha_{n}\left\|f\left(x_{n}\right)-T_{n} u_{n}\right\|\left\|u_{n}-p\right\| .
\end{aligned}
$$

Therefore,

$$
\begin{aligned}
\left\|x_{n}-u_{n}\right\|^{2} \leq & \left\|x_{n}-p\right\|^{2}-\left\|x_{n+1}-p\right\|^{2}+\alpha_{n}^{2}\left\|f\left(x_{n}\right)-T_{n} u_{n}\right\|^{2} \\
& +2 r_{n}\left\|x_{n}-u_{n}\right\|\left\|A x_{n}-A p\right\|+2 \alpha_{n}\left\|f\left(x_{n}\right)-T_{n} u_{n}\right\|\left\|u_{n}-p\right\| \\
\leq & \left(\left\|x_{n}-p\right\|+\left\|x_{n+1}-p\right\|\right)\left\|x_{n+1}-x_{n}\right\|+\alpha_{n}^{2}\left\|f\left(x_{n}\right)-T_{n} u_{n}\right\|^{2} \\
& +2 r_{n}\left\|x_{n}-u_{n}\right\|\left\|A x_{n}-A p\right\|+2 \alpha_{n}\left\|f\left(x_{n}\right)-T_{n} u_{n}\right\|\left\|u_{n}-p\right\| .
\end{aligned}
$$

Then $\left(B_{1}\right)$, Step 2 and (3.12) show that

$$
\lim _{n \rightarrow \infty}\left\|x_{n}-u_{n}\right\|=0 .
$$

From (3.4) we get

$$
\begin{aligned}
\left\|T_{n} u_{n}-u_{n}\right\| & \leq\left\|T_{n} u_{n}-x_{n+1}\right\|+\left\|x_{n}-x_{n+1}\right\|+\left\|x_{n}-u_{n}\right\| \\
& \leq \alpha_{n}\left\|f\left(x_{n}\right)-T_{n} u_{n}\right\|+\left\|x_{n}-x_{n+1}\right\|+\left\|x_{n}-u_{n}\right\| .
\end{aligned}
$$

So $\lim _{n \rightarrow \infty}\left\|T_{n} u_{n}-u_{n}\right\|=0$. Observe that

$$
\begin{aligned}
\left\|P_{C}\left(I-\lambda_{n} \nabla g\right) u_{n}-u_{n}\right\| & =\left\|s_{n} u_{n}+\left(1-s_{n}\right) T_{n} u_{n}-u_{n}\right\| \\
& =\left(1-s_{n}\right)\left\|T_{n} u_{n}-u_{n}\right\| \\
& \leq\left\|T_{n} u_{n}-u_{n}\right\|,
\end{aligned}
$$

where $s_{n}=\frac{2-\lambda_{n} L}{4}$. Hence

$$
\begin{aligned}
\left\|P_{C}\left(I-\frac{2}{L} \nabla g\right) u_{n}-u_{n}\right\| \leq & \left\|P_{C}\left(I-\frac{2}{L} \nabla g\right) u_{n}-P_{C}\left(I-\lambda_{n} \nabla g\right) u_{n}\right\| \\
& +\left\|P_{C}\left(I-\lambda_{n} \nabla g\right) u_{n}-u_{n}\right\| \\
\leq & \left\|\left(I-\frac{2}{L} \nabla g\right) u_{n}-\left(I-\lambda_{n} \nabla g\right) u_{n}\right\| \\
& +\left\|P_{C}\left(I-\lambda_{n} \nabla g\right) u_{n}-u_{n}\right\| \\
\leq & \left(\frac{2}{L}-\lambda_{n}\right)\left\|\nabla g\left(u_{n}\right)\right\|+\left\|T_{n} u_{n}-u_{n}\right\| .
\end{aligned}
$$


Applying the conditions $s_{n} \rightarrow 0$ (which is equivalent to $\lambda_{n} \rightarrow \frac{2}{L}$ ) and $\lim _{n \rightarrow \infty}\left\|T_{n} u_{n}-u_{n}\right\|=0$, we conclude that

$$
\left\|P_{C}\left(I-\frac{2}{L} \nabla g\right) u_{n}-u_{n}\right\|=0 .
$$

Step 4. We claim that

$$
\limsup _{n \rightarrow \infty}\left\langle f(q)-q, x_{n}-q\right\rangle \leq 0,
$$

where $q=P_{U \cap E P} f(q)$. To show this, choose a subsequence $\left\{u_{n_{i}}\right\}$ of $\left\{u_{n}\right\}$ such that

$$
\limsup _{n \rightarrow \infty}\left\langle(I-f) q, q-u_{n}\right\rangle=\lim _{i \rightarrow \infty}\left\langle(I-f) q, q-u_{n_{i}}\right\rangle .
$$

Since $\left\{u_{n_{i}}\right\}$ is bounded in $C$, without loss of generality, we assume that $u_{n_{i}} \rightarrow z \in C$. Next, we show that $z \in U \cap E P$. Since $\nabla g$ is $\frac{1}{L}$-ism, $P_{C}\left(I-\frac{2}{L} \nabla g\right)$ is nonexpansive self-mapping on $C$. Indeed,

$$
\begin{aligned}
\| P_{C}\left(I-\frac{2}{L} \nabla g\right) x-P_{C}(I- & \left.\frac{2}{L} \nabla g\right) y\left\|^{2} \leq\right\|\left(I-\frac{2}{L} \nabla g\right) x-\left(I-\frac{2}{L} \nabla g\right) y \|^{2} \\
= & \left\|x-y-\frac{2}{L}(\nabla g(x)-\nabla g(y))\right\|^{2} \\
= & \|x-y\|^{2}-\frac{4}{L}\langle(x-y, \nabla g(x)-\nabla g(y)\rangle \\
& +\frac{4}{L^{2}}\|\nabla g(x)-\nabla g(y)\|^{2} \\
\leq & \|x-y\|^{2}-\frac{4}{L^{2}}\|\nabla g(x)-\nabla g(y)\|^{2} \\
& +\frac{4}{L^{2}}\|\nabla g(x)-\nabla g(y)\|^{2} \\
= & \|x-y\|^{2}
\end{aligned}
$$

for all $x, y \in C$. Therefore, from (3.15) and Lemma 2.2 we obtain $z=$ $P_{C}\left(I-\frac{2}{L} \nabla g\right) z$. This implies that $z \in U$. Now, we show that $z \in E P$. By $u_{n}=Q_{r_{n}}\left(x_{n}-r_{n} A x_{n}\right)$, we can write

$$
\phi\left(u_{n}, y\right)+\left\langle A x_{n}, y-u_{n}\right\rangle+\frac{1}{r_{n}}\left\langle y-u_{n}, u_{n}-x_{n}\right\rangle \geq 0 \text { for all } y \in C .
$$

From $\left(A_{2}\right)$ we get

$$
\left\langle A x_{n}, y-u_{n}\right\rangle+\frac{1}{r_{n}}\left\langle y-u_{n}, u_{n}-x_{n}\right\rangle \geq \phi\left(y, u_{n}\right) \text { for all } y \in C .
$$

Replacing $n$ by $n_{i}$, we have

$$
\left\langle A x_{n_{i}}, y-u_{n_{i}}\right\rangle+\frac{1}{r_{n_{i}}}\left\langle y-u_{n_{i}}, u_{n_{i}}-x_{n_{i}}\right\rangle \geq \phi\left(y, u_{n_{i}}\right) \text { for all } y \in C
$$


Set $y_{t}=t y+(1-t) z$ for all $t \in(0,1]$ and $y \in C$. Then $y_{t} \in C$. So, from (3.16) we obtain

$$
\begin{aligned}
\left\langle y_{t}-u_{n_{i}}, A y_{t}\right\rangle \geq & \left\langle y_{t}-u_{n_{i}}, A y_{t}\right\rangle-\left\langle A x_{n_{i}}, y_{t}-u_{n_{i}}\right\rangle \\
& -\left\langle y_{t}-u_{n_{i}}, \frac{u_{n_{i}}-x_{n_{i}}}{r_{n_{i}}}\right\rangle+\phi\left(y_{t}, u_{n_{i}}\right) \\
= & \left\langle y_{t}-u_{n_{i}}, A y_{t}-A u_{n_{i}}\right\rangle+\left\langle y_{t}-u_{n_{i}}, A u_{n_{i}}-A x_{n_{i}}\right\rangle \\
& -\left\langle y_{t}-u_{n_{i}}, \frac{u_{n_{i}}-x_{n_{i}}}{r_{n_{i}}}\right\rangle+\phi\left(y_{t}, u_{n_{i}}\right) .
\end{aligned}
$$

Since $\lim _{i \rightarrow \infty}\left\|u_{n_{i}}-x_{n_{i}}\right\|=0$, we have $\lim _{i \rightarrow \infty}\left\|A u_{n_{i}}-A x_{n_{i}}\right\|=0$. Further, monotonicity of $A$ gives $\left\langle y_{t}-u_{n_{i}}, A y_{t}-A u_{n_{i}}\right\rangle \geq 0$. So, passing to the limit with $i \rightarrow \infty$ in the above inequality and using $\left(A_{4}\right)$, we get

$$
\left\langle y_{t}-z, A y_{t}\right\rangle \geq \phi\left(y_{t}, z\right) \text {. }
$$

From $\left(A_{1}\right),\left(A_{2}\right)$ and $(3.17)$ we see that

$$
\begin{aligned}
0=\phi\left(y_{t}, y_{t}\right) & \leq t \phi\left(y_{t}, y\right)+(1-t) \phi\left(y_{t}, z\right) \leq t \phi\left(y_{t}, y\right)+(1-t)\left\langle y_{t}-z, A y_{t}\right\rangle \\
& =t \phi\left(y_{t}, y\right)+(1-t) t\left\langle y-z, A y_{t}\right\rangle,
\end{aligned}
$$

hence

$$
0 \leq \phi\left(y_{t}, y\right)+(1-t)\left\langle y-z, A y_{t}\right\rangle
$$

Letting $t \rightarrow 0$, we get

$$
0 \leq \phi(z, y)+\langle y-z, A z\rangle \text { for all } y \in C .
$$

This implies $z \in E P$. Since $q=P_{U \cap E P} f(q)$,

$$
\begin{aligned}
\limsup _{n \rightarrow \infty}\left\langle(I-f)(q), q-x_{n}\right\rangle & =\lim _{i \rightarrow \infty}\left\langle(I-f)(q), q-x_{n_{i}}\right\rangle \\
& =\lim _{i \rightarrow \infty}\left\langle(I-f)(q), q-u_{n_{i}}\right\rangle \\
& =\lim _{i \rightarrow \infty}\langle(I-f)(q), q-z\rangle \leq 0 .
\end{aligned}
$$

Step 5. We claim, $\left\{u_{n}\right\}$ and $\left\{x_{n}\right\}$ converge strongly to $q$. From (3.4) and Lemma 2.1 we get

$$
\begin{aligned}
\left\|x_{n+1}-q\right\|^{2}= & \left\|\alpha_{n} f\left(x_{n}\right)+\left(1-\alpha_{n}\right) T_{n} u_{n}-q\right\|^{2} \\
= & \left\|\alpha_{n}\left(f\left(x_{n}\right)-f(q)\right)+\alpha_{n}(f(q)-q)+\left(1-\alpha_{n}\right)\left(T_{n} u_{n}-T_{n} q\right)\right\|^{2} \\
\leq & \left(1-\alpha_{n}\right)^{2}\left\|T_{n} u_{n}-T_{n} q\right\|^{2} \\
& +2 \alpha_{n}\left\langle f\left(x_{n}\right)-f(q)-(I-f) q, x_{n+1}-q\right\rangle .
\end{aligned}
$$

This implies

$$
\begin{aligned}
\left\|x_{n+1}-q\right\|^{2} \leq & \left(1-\alpha_{n}\right)^{2}\left\|x_{n}-q\right\|^{2}+2 \alpha_{n} k\left\|x_{n}-q\right\|\left\|x_{n+1}-q\right\| \\
& +2 \alpha_{n}\left\langle-(I-f) q, x_{n+1}-q\right\rangle \\
\leq & \left(1-\alpha_{n}\right)^{2}\left\|x_{n}-q\right\|^{2}+\alpha_{n} k\left(\left\|x_{n}-q\right\|^{2}+\left\|x_{n+1}-q\right\|^{2}\right) \\
& +2 \alpha_{n}\left\langle-(I-f) q, x_{n+1}-q\right\rangle .
\end{aligned}
$$


Then

$$
\begin{aligned}
\left\|x_{n+1}-q\right\|^{2} \leq & \frac{1-2 \alpha_{n}+\alpha_{n} k}{1-\alpha_{n} k}\left\|x_{n}-q\right\|^{2}+\frac{\alpha_{n}^{2}}{1-\alpha_{n} k}\left\|x_{n}-q\right\|^{2} \\
& +\frac{2 \alpha_{n}}{1-\alpha_{n} k}\left\langle-(I-f) q, x_{n+1}-q\right\rangle \\
\leq & \left(1-2(1-k) \alpha_{n}\right)\left\|x_{n}-q\right\|^{2}+\frac{\alpha_{n}^{2}}{1-\alpha_{n} k}\left\|x_{n}-q\right\|^{2} \\
& +\frac{2 \alpha_{n}}{1-\alpha_{n} k}\left\langle-(I-f) q, x_{n+1}-q\right\rangle \\
\leq & \left(1-2(1-k) \alpha_{n}\right)\left\|x_{n}-q\right\|^{2} \\
& +2(1-k) \alpha_{n}\left(\frac{\alpha_{n}}{2(1-k)\left(1-\alpha_{n} k\right)} M^{*}\right. \\
& \left.\quad+\frac{1}{(1-k)\left(1-\alpha_{n} k\right)}\left\langle-(I-f) q, x_{n+1}-q\right\rangle\right) \\
& \left(1-2(1-k) \alpha_{n}\right)\left\|x_{n}-q\right\|^{2}+2(1-k) \alpha_{n} \delta_{n},
\end{aligned}
$$

where $M^{*}=\sup \left\{\left\|x_{n}-q\right\|^{2}: n \geq 1\right\}$ and

$$
\delta_{n}=\frac{\alpha_{n}}{2(1-k)\left(1-\alpha_{n} k\right)} M^{*}+\frac{1}{(1-k)\left(1-\alpha_{n} k\right)}\left\langle-(I-f) q, x_{n+1}-q\right\rangle .
$$

It is easy to see that $\lim _{n \rightarrow \infty} 2(1-k) \alpha_{n}=0, \sum_{n=1}^{\infty} 2(1-k) \alpha_{n}=\infty$ and $\limsup _{n \rightarrow \infty} \delta_{n} \leq 0$. Hence, by Lemma 2.10, $\left\{x_{n}\right\}$ converges strongly to $q$. Consequently, $\left\{u_{n}\right\}$ converges strongly to $q$. This completes the proof.

Remark 3.4. Theorem 3.3 is a generalization of [13, Theorem 3.2]. To see this, set $A=0$ in Theorem 3.3 and assume $r_{n} \geq a>0$ (it is not necessary to assume $\left.\left\{r_{n}\right\} \subset[a, b] \subset(0,2 \alpha)\right)$.

4. Numerical test. In this section, we give an example to illustrate the scheme (3.4) given in Theorem 3.3.

Example 4.1. Let $C=[-1,1] \subset H=\mathbb{R}$ and define

$$
\phi(x, y)=-5 x^{2}+x y+4 y^{2} .
$$

First, we verify that $\phi$ satisfies the conditions $\left(A_{1}\right)-\left(A_{4}\right)$ as follows:

$\left(A_{1}\right) \phi(x, x)=-5 x^{2}+x^{2}+4 x^{2}=0$, for all $x \in[-1,1]$;

$\left(A_{2}\right) \phi(x, y)+\phi(y, x)=-(x-y)^{2} \leq 0$, for all $x, y \in[-1,1]$;

$\left(A_{3}\right)$ For all $x, y, z \in[-1,1]$,

$$
\limsup _{t \rightarrow 0^{+}} \phi(t z+(1-t) x, y)=-5 x^{2}+x y+4 y^{2} \leq \phi(x, y) .
$$

$\left(A_{4}\right)$ For all $x \in[-1,1], \Phi(y)=\phi(x, y)=-5 x^{2}+x y+4 y^{2}$ is a lower semicontinuous convex function. 
From Lemma 2.4 we see that $Q_{r}$ is single-valued, for all $r>0$. Now, we deduce a formula for $Q_{r}(x)$. For any $y \in[-1,1]$ and $r>0$, we have

$\phi(z, y)+\frac{1}{r}\langle y-z, z-x\rangle \geq 0 \Leftrightarrow 4 r y^{2}+((r+1) z-x) y+x z-(5 r+1) z^{2} \geq 0$.

Set $G(y)=4 r y^{2}+((r+1) z-x) y+x z-(5 r+1) z^{2}$. Then $G(y)$ is a quadratic function of $y$ with coefficients $a=4 r, b=(r+1) z-x$ and $c=x z-(5 r+1) z^{2}$. So its discriminate $\Delta=b^{2}-4 a c$ is

$$
\begin{aligned}
\Delta & =[(r+1) z-x]^{2}-16 r\left(x z-(5 r+1) z^{2}\right) \\
& =(r+1)^{2} z^{2}-2(r+1) x z+x^{2}-16 r x z+\left(80 r^{2}+16 r\right) z^{2} \\
& =[(9 r+1) z-x]^{2} .
\end{aligned}
$$

Since $G(y) \geq 0$ for all $y \in C$, this is true if and only if $\Delta \leq 0$. That is, $[(9 r+1) z-x]^{2} \leq 0$. Therefore, $z=\frac{x}{9 r+1}$, which yields $Q_{r}(x)=\frac{x}{9 r+1}$. So, from Lemma 2.4 we get $E P(\phi)=\{0\}$. Let $\alpha_{n}=\frac{1}{n}, \lambda_{n}=\frac{1}{4}, r_{n}=1$, for all $n \in \mathbb{N}, A x=\frac{99}{100} x$ and $f(x)=\frac{1}{2} x, g(x)=x^{2}$. Hence $U \cap E P=\{0\}, A$ is $\frac{99}{100}$-ism and $s_{n}=\frac{2-\lambda_{n} L}{4}=\frac{3}{8}$. Also, $T_{n} x=\frac{1}{5} x$, for all $x \in[-1,1]$. Indeed,

$$
P_{C}\left(I-\lambda_{n} \nabla g\right) x=P_{[-1,1]}\left(x-\frac{x}{2}\right)=\frac{x}{2}=\frac{3}{8} x+\frac{5}{8} T_{n} x \text { for all } x \in[-1,1] .
$$

So, $T_{n} x=\frac{1}{5} x$ for all $x \in[-1,1]$. Then, from Lemma 2.10 we see that the sequences $\left\{x_{n}\right\}$ and $\left\{u_{n}\right\}$, generated iteratively by

$$
\left\{\begin{array}{l}
u_{n}=Q_{r_{n}}\left(x_{n}-r_{n} A x_{n}\right)=Q_{1}\left(x_{n}-\frac{99}{100} x_{n}\right)=\frac{1}{1000} x_{n}, \\
x_{n+1}=\frac{1}{2 n} x_{n}+\left(1-\frac{1}{n}\right) T_{n}\left(\frac{1}{1000} x_{n}\right)=\frac{n+2499}{5000 n} x_{n}
\end{array}\right.
$$

converge strongly to $0 \in U \cap E P$, where $0=P_{U \cap E P}\left(\frac{1}{2} I\right)(0)$.

Acknowledgment. The author would like to thank the referee for his valuable comments.

\section{REFERENCES}

[1] Aoyama, K., Kimura, Y., Takahashi, W., Toyoda, M., Approximation of common fixed points of a countable family of nonexpansive mappings in a Banach space, Nonlinear Anal. 67 (2007), 2350-2360.

[2] Blum, E., Oettli, W., From optimization and variatinal inequalities to equilibrium problems, Math. Student. 63 (1994), 123-145.

[3] Bertsekas, D. P., Gafin, E. M., Projection methods for variational inequalities with applications to the traffic assignment problem, Math. Program. Stud. 17 (1982), 139159.

[4] Byrne, C., A unified treatment of some iterative algorithms in signal processing and image reconstruction, Inverse Probl. 20 (2004), 103-120.

[5] Combettes, P. L., Hirstoaga, S. A., Equilibrium programming in Hilbert spaces, J. Nonlinear Convex Anal. 6 (2005), 117-136. 
[6] Goebel, K., Kirk, W. A., Topics in Metric Fixed Point Theory, Cambridge Stud. Adv. Math. 28, Cambridge Univ. Press, Cambridge, 1990.

[7] Han, D., Lo, H. K., Solving non-additive traffic assignment problems: A descent method for co-coercive variational inequalities, Eur. J. Oper. Res. 159 (2004), 529544.

[8] Jung, J. S., A general composite iterative method for equilibrium problems and fixed point problems, J. Comput. Anal. Appl. 12 (1-A) (2010), 124-140.

[9] Moudafi, A., Théra, M., Proximal and dynamical approaches to equilibrium problems, in: Ill-posed Variational Problems and Regularization Techniques, Lecture Notes in Economics and Mathematical Systems, 477, Springer-Verlag, Berlin, 1999, 187-201.

[10] Peng, J.-W., Yao, J.-Ch., A viscosity approximation scheme for system of equilibrium problems, nonexpansive mappings and monotone mappings, Nonlinear Anal. 71 (12) (2009), 6001-6010.

[11] Plubtieg, S., Punpaeng, R., A general iterative method for equilibrium problems and fixed point problems in Hilbert spaces, J. Math. Anal. Appl. 336 (2007), 455-469.

[12] Razani, A., Yazdi, M., Viscosity approximation method for equilibrium and fixed point problems, Fixed Point Theory. 14 (2) (2013), 455-472.

[13] Tian, M., Liu, L., Iterative algorithms based on the viscosity approximation method for equilibrium and constrained convex minimization problem, Fixed Point Theory Appl. 2012:201 (2012), 1-17.

[14] Wang, S., Hu, Ch., Chai, G., Strong convergence of a new composite iterative method for equilibrium problems and fixed point problems, Appl. Math. Comput. 215 (2010), 3891-3898.

[15] Xu, H.-K., Iterative algorithms for nonlinear operators, J. London Math. Soc. (2) 66 (2002), 240-256.

[16] Xu, H.-K., An iterative approach to quadratic optimization, J. Optim. Theory Appl. 116 (2003), 659-678.

[17] Xu, H.-K., Averaged mappings and the gradient-projection algorithm, J. Optim. Theory Appl. 150 (2011), 360-378.

[18] Yazdi, M., New iterative methods for equilibrium and constrained convex minimization problems, Asian-Eur. J. Math. 12 (3) (2019), 12 pp.

M. Yazdi

Department of Mathematics

Malard Branch

Islamic Azad University

Malard

Iran

e-mail: msh_yazdi@yahoo.com

Received May 1, 2019 